\title{
Comparison of the graphitizabilities of heat-treated coal tar and its mesophase pitches
}

\author{
A. MANI, B. C. PAI*, KALYANI VIJAYAN $\ddagger$ \\ Materials Science Division, National Aeronautical Laboratory, Bangafore 560 077, India
}

Formation of graphitizing carbons via a mesophase was first reported by Brooks and Taylor [1]. Owing to the inherent structural order of the mesophase, it may be anticipated that the graphitizability of carbon from its mesophase would be higher than that of the same carbon, heat-treated from the isotropic phase. However, it has been reported by Yamada $\boldsymbol{e t}$ al. [2] that the graphitizability of some mesophase microbeads is not good. With the view to obtain quantitative estimates of the graphitizabilities of a graphitizable carbon and its mesophase, X-ray diffraction studies on identically heat-treated coal tar (CT) and its mesophase (MP) pitches have been carried out. Details of the preparation and metallographic characterization of the MP pitch have been published elsewhere [3].

Samples of MP and CT pitches were heat treated at 1050,3400 and $2700^{\circ} \mathrm{C}$ using a graphite furnace and nitrogen atmosphere. At each heat-treatment temperature (HTT), the samples were retained for different residence times (RT). Debye-Scherrer photographs from identically treated CT and MP specimens were recorded using $\mathrm{CuK} \alpha$ radiation. The diffraction patterns were scanned on a SCANDIG-3 microdensitometer using a $100 \mu \mathrm{m}$ scanning aperture.

Comparison of the diffraction patterns indicate that the overall behaviour of heat-treated $\mathrm{CT}$ and MP specimens is very similar, i.e. (i) at $\mathrm{HTT}=1050^{\circ} \mathrm{C}$, the observed diffuse haloes corresponding to the reflec-

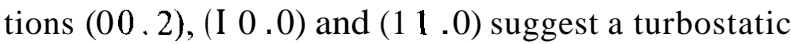
structure; (ii) the increase in sharpness and the number of observed reflections from HTT $=2400$ and 2700' C suggest an improvement in three-dimensional ordering, growth of crystallites and reduction in lattice strain; (iii) at HTT $=2400 \mathrm{C}$, the diffuse band observed on the low-angle side of the (00.2) maxima suggests the presence of unorganized material with higher d-spacing. However, the non-occurrence of this band at HTT $=2700 \mathrm{C}$, suggests that at higher HTTs, the heat-treated product is more homogeneous.

Despite these similarities in the overall characteristics, diffraction patterns from $\mathrm{CT}$ and MP specimens exhibit remarkable differences in their details. Under identical conditions, MP specimens are characterized by diffraction lines which are more intense and sharper than those from CT specimens. Also, the MP patterns include a higher number of high-angle reflections. These features suggest that the crystal structures of MP specimens are perhaps more ordered and graphite-like than the corresponding CT specimens. Details of the $\mathrm{X}$-ray results which support this view are presented below.

It is found (Fig. la) that with increase in HTT, both $\mathrm{CT}$ and MP specimens exhibit a large initial drop in the interlayer spacing, $d_{00}$, value, followed by a progressively slower variation. The observed feature of

$$
d_{00.2}(\mathrm{MP})<d_{00.2}(\mathrm{CT})
$$

throughout the HTT range suggests that the graphitizability [4] of the MP specimens is consistently higher than that of the CT specimens. The diminution in the
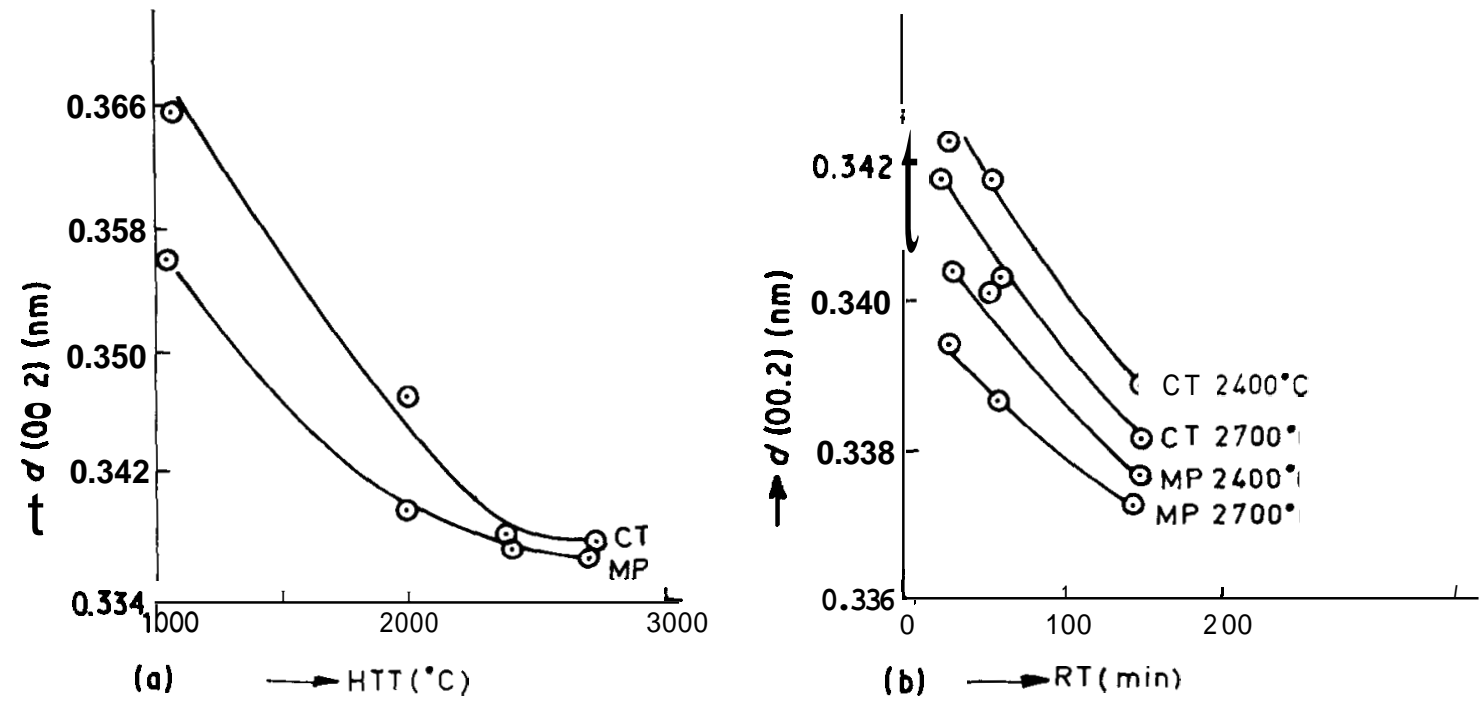

Figure I Variation of the interlayer spacing $d_{00} 2$ with (a) HTT and (b) RT.

*Present address: MGC Division, RRL, Trivandrum, India

\$To whom correspondence should be addressed. 


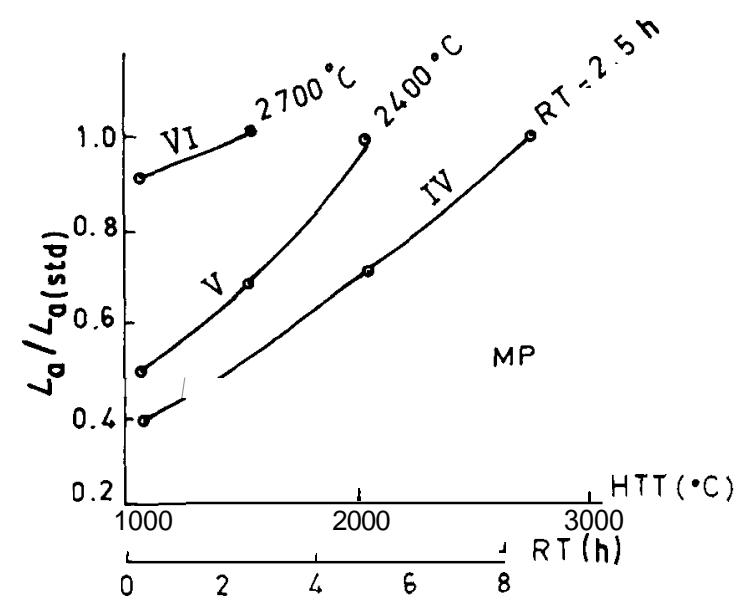

(a)

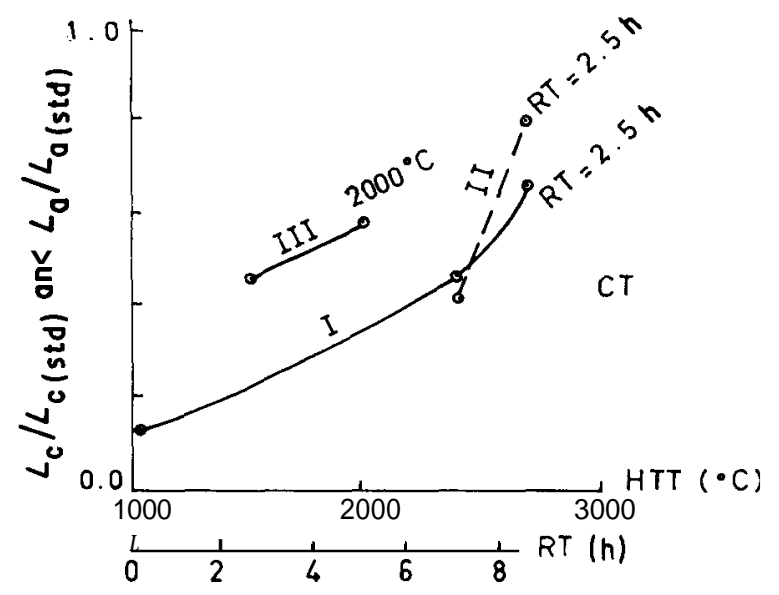

(c)

spacing between curves (i) and (ii) in Fig. la suggests that although the graphitizabilities of the CT and MP specimens differ substantially at early stages of heattreatment, with increase in HTT, the distinction between the CT and MP structures diminishes. The variation of the $d_{00}$ values with RT shown in Fig. $1 \mathrm{~b}$ supports this view.

The variation in the crystallite height $\left(L_{\mathrm{c}}\right)$ and width $\left(L_{\mathrm{a}}\right)$ have been analysed from the respective half-value breadths $(\beta)$ of the $(00 . l)$ and $\left(\begin{array}{ll}1 & 1.0) \\ \text { reflections. The }\end{array}\right.$ crystallite dimensions have been estimated relative to

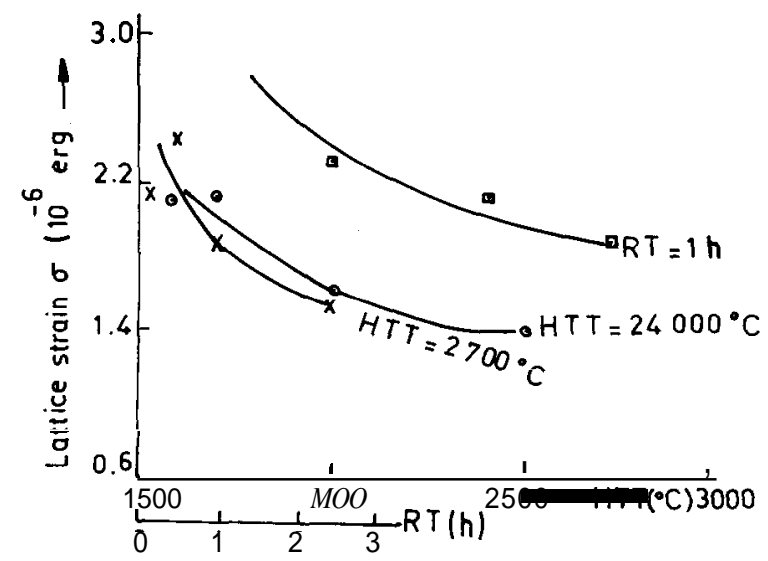

Figure 3 Variation of lattice strain of MP specimens with HTT and RT.

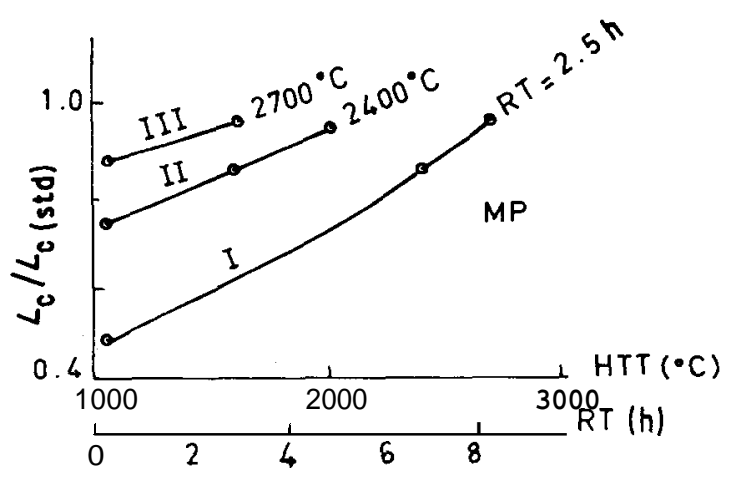

(b)

Figure 2 Variation of crystallite dimensions. (a) $L_{\mathrm{a}} / L_{\text {a(sid) }}$ against HTT and RT of MP specimens. (b) $L_{\mathrm{c}} / L_{\mathrm{css} \text { (d) }}$ against HTT and RT of MP specimens. (c) $L_{\mathrm{a}} / L_{\mathrm{a}(\text { std })}$ and $L_{\mathrm{c}} / L_{\mathrm{c}(\mathrm{std})}$ (I and III) against HTT and $\mathrm{RT}$ of $\mathrm{CT}$ specimens.

those of commercially available ultra-F-purity graphite, the parameters of which are denoted by "std". The variations of $L_{\mathrm{a}} / L_{\mathrm{a}(\mathrm{std})}$ and $L_{\mathrm{c}} / L_{\mathrm{c} \text { (std) }}$ with HTT and RT are shown in Fig. 2. It is found that at HTT $=2400 " \mathrm{C}$, the reflections from $\mathrm{CT}$ specimens are significantly broader than those from MP specimens, pointing out that despite the identical treatment, CT specimens are characterized by smaller crystallite size and higher lattice strain. However, at HTT $=2700^{\circ} \mathrm{C}$, the dissimilarities in the half value breadths of reflections from CT and MP specimens are less conspicuous. These features lend further support to the view that the structural differences between CT and MP specimens decrease with increase in HTT.

Values of the lattice strain estimated from $\beta \cos \theta$ against $l^{2}$ curves [5] of the MP specimens are shown in Fig. 3. The decrease in lattice strain with HTT indicates the progress of graphitization. On account of the low intensity of the relevant reflections, similar estimates of lattice strain could not be obtained for the CT specimens. However, the poor quality of the diffraction data from the $\mathrm{CT}$ specimens provides ample evidence that CT specimens are more disordered than the corresponding MP specimens.

Values of the graphitization index [6] presented in Table I provides further support for the conclusion derived on the basis of the $d_{00.2}$ values, crystallite dimensions and lattice strain, namely, that the graphitizability of MP specimens is superior to that of the corresponding CT specimens.

TA B LE I Values of graphitization index

\begin{tabular}{llll}
\hline HTT & R T & G I. & \\
\cline { 3 - 4 }$(\mathrm{C})$ & $(\min )$ & $\mathrm{MP}$ & $\mathrm{CT}$ \\
\hline 2400 & 10 & 69 & $\begin{array}{l}\text { Not measureable } \\
\end{array}$ \\
& 60 & 31 & 78 \\
& 300 & 9 & 39 \\
2700 & 10 & 49 & 51 \\
& 60 & 24 & 36 \\
& 150 & 12 & 16 \\
\hline
\end{tabular}

G.I. $=\operatorname{area}(10.0+10.1) / \operatorname{area}(10.2)$ 


\section{References}

I. J. D. BROOKS and G. H. TAYLOR, Carbon 3 (1965) 185.

2. Y. YAMADA, T. IMAMURA, H. KAKIYAMA, H. HONDA, S. OI and K. FUKUDA, ibid. 12 (1974) 307.

3. B. C PAI, M. A. PARAMESWARA, M. K. SRIDHAR and P. KANAKALATHA, NAL Publication, TM-MT-4-83.

4. D. B. FISCHBACH, Chem. Phys. Carbon 7 (1971) I.

5. P. A. THROWER and D. C. NAGLE, Carbon 11 (1973)
663.

6. J. THOMAS Jr, N. E. WESTON and T. E. O'CONNOR, J. Am. Chem. Soc. 84 (1963) 4619.

\section{Received 24 September}

and accepted 30 October 1985 